\title{
GEOQUÍMICA DOS GNAISSES TTGs E GRANITÓIDES NEOARQUEANOS DO COMPLEXO BELO HORIZONTE, QUADRILÁTERO FERRÍFERO, MINAS GERAIS
}

\author{
CARLOS MAURÍCIO NOCE* , WILSON TEIXEIRA** \& NUNO MACHADO***
}

\begin{abstract}
GEOCHEMISTRY OF TTG GNEISSES AND NEOARCHEAN GRANITOIDS, BELO HORIZONTE COMPLEX, QUADRILÁTERO FERRIFERO, MINAS GERAIS The Archean crust of the Quadrilatero Ferrífero region comprises a greenstone belt (Rio das Velhas Supergroup) surrounded by metamorphic complexes (e.g. Belo Horizonte, Bonfim and Bação metamorphic complexes). The Belo Horizonte Complex is located to the north of the Quadrilátero Ferrifero. It is composed of a migmatitic banded gneiss with schlieren and stromatic structures and mafic enclaves, and intrusive granitoid bodies. The banded gneiss is the dominant rock type within the Belo Horizonte Complex and is hereafter referred to as Belo Horizonte gneiss. The major and trace element characteristics of the Belo Horizonte gneiss are similar to those of Archean tonalite-trondhjemite-granodiorite (TTG) suites described from other continents. The gneiss protholit was probably emplaced in the 3.0-2.9 Ga time span. Neoarchean granitogenesis (ca. $2.7 \mathrm{Ga}$ ) in the Belo Horizonte Complex is represented by the Santa Luzia, General Carneiro and Ibirité granitoids. They are well foliated and rather homogeneous plutons. The Santa Luzia and General Carneiro plutons are calc-alkaline and slightly peraluminous granites with génesis probably related to the reworking of the older TTG gneisses.
\end{abstract}

Keywords: geochemistry, Archean crust, Quadrilátero Ferrífero

RESUMO A crosta arquearia da região do Quadrilátero Ferrífero é constituída por uma sequência do tipo greenstone belt (Supergrupo Rio das Velhas) circundada por diversos complexos metamórficos (e.g. complexos metamórficps de Belo Horizonte, Bonfim e Bacão). O Complexo Belo Horizonte situa-se a norte do Quadrilátero Ferrífero. E constituído por um gnaisse bandado, migmatizado, exibindo estrutura schlieren ou estromática e frequentes encraves máficos, além de corpos granitóides intrusivos. Este gnaisse bandado representa o litotipo dominante do Complexo Belo Horizonte e foi denominado Gnaisse Belo Horizonte. Sua composição química é semelhante a das suites tonalito-trondhjemito-granodiorito (TTG) arqueanas descritas em outros continentes. 0 protólito do Gnaisse Belo Horizonte foi gerado, possivelmente, no período 3,0-2,9 Ga. A granitogênese neoarqueana (ca. $2,7 \mathrm{Ga}$ ) no Complexo Belo Horizonte é representada pelos granitóides de Santa Luzia, General Carneiro e Ibirité. Constituem plútons bem foliados e bastante homogêneos. Os corpos de Santa Luzia e General Carneiro são granitos cálcio-alcalinos e ligeiramente peraluminosos, aparentemente derivados do retrabalhamento dos gnaisses TTG.

Palavras-chaves: geoquímica, crosta arqueana, Quadrilátero Ferrífero

INTRODUÇ̃̃O O contexto geológico do Quadrilátero Ferrífero compreende: (i) terrenos granito-gnáissicos; (ii) greenstone belts arqueanos, representados pelo Supergrupo Rio das Velhas e faixas correlatas; (iii) unidades metassedimentares do Paleo e Mesoproterozóico (Supergrupo Minas, Grupo Itacolomi e Supergrupo Espinhaço). Os terrenos granito-gnáissicos compreendem diversos complexos, conforme divisão esboçada por Herz (1970). Estes são os complexos Caeté, Bonfim, Bação e Belo Horizonte. Os contatos com as unidades supracrustais adjacentes são de natureza tectônica. Esses complexos metamórficos são constituídos, majoritariamente, por ortognaisses do tipo TTG (Figueiredo \& Barbosa 1993), migmatizados ou não. Apresentam intrusões granitóides, na forma de veios ou corpos circunscritos, anfibolitos e pegmatitos.

Os complexos metamórficos do Quadrilátero Ferrífero carecem, de modo geral, de um detalhamento geológico. Carneiro (1992), estudando a porção setentrional do Complexo Bonfim, constatou a presença de dois tipos de gnaisses; o Gnaisse Alberto Flores e o Gnaisse Souza Noschese, definidos originalmente por Herz (1970). O primeiro é bandado e localmente migmatizado, possuindo composição granodiorítica a tonalítica-trondhjemítica e exibindo marcante foliação milonítica N-S. O segundo possui composição granítica e foliação menos desenvolvida. Carneiro (1992) observou também a ocorrência de duas gerações de granitóides, designados Tonalitos Samambaia e Granito Brumadinho. Este último ocorre na forma de veios fracamente deformados, cortando a foliação N-S regional dos gnaisses mais antigos (Gnaisse
Alberto Flores). Idades U-Pb confirmaram a idade arqueana do Complexo Bonfim. O metamorfismo do Gnaisse Alberto Flores e a intrusão dos Tonalitos Samambaia foram datados em, respectivamente, $2772 \pm 6 \mathrm{Ma}$ e $2780+3 /-2 \mathrm{Ma}$. A intrusão do Granito Brumadinho ocorreu em 2703+24/-20 Ma (Machado \& Carneiro 1992).

No presente trabalho são apresentados os dados geoquímicos referentes às rochas do Complexo Belo Horizonte, situado imediatamente a norte do Quadrilátero Ferrífero. $\mathrm{O}$ Complexo Belo Horizonte, semelhantemente ao Complexo Bonfim, formou-se durante o Arqueano, embora tenha sido mais afetado pelo Evento Transamazônico, por volta de 2050 Ma (Machado et al. 1992, Noce 1995).

COMPLEXO BELO HORIZONTE Descrição geológica Os trabalhos anteriores existentes sobre o Complexo Belo Horizonte são os da equipe USGS-DNPM, mais especificamente os de Gair (1962), Pomerene (1964) e Herz (1970). Segundo este último autor, a maior parte da área a norte da Serra do Curral é constituída por um gnaisse de composição granodiorítica apresentando bandamento composicional. Estas rochas são consideradas similares ao Granito de Alberto Flores (Complexo Bonfim) e também correlacionáveis ao Granito-Gnaisse de Itabirito (Complexo Bação). Herz (1970) assinala, ainda, a presença de dois pequenos corpos granitóides, designados Granito Marzagão e Granito Morro da Pedra. Este último é de idade transamazônica (Noce 1995) e não será abordado neste trabalho.

* Centro de Pesquisa Prof. Manuel Teixeira da Costa (CPMTC), Instituto de Geociências, Universidade Federal de Minas Gerais, Av. Antônio Carlos, 6627, 31270-901, Belo Horizonte, MG, Brasil. End. eletrônico: noce@csr.ufmg.br

** Departamento de Geologia Geral, Instituto de Geociências, Universidade de São Paulo, caixa postal 11348, 5422-970, São Paulo, SP, Brasil.

*** Centre de Recherche en Géochimie Isotopique et en Géochronologie (GEOTOP), Université du Québec à Montreal, case postale 8888, succ. A, H3C 3P8, Montreal, Qc., Canadá. 
O presente estudo revelou a presença de corpos granitóides foliados, intrusivos nos gnaisses, com dimensões de alguns quilómetros. Foram também incluídas no Complexo Belo Horizonte duas faixas isoladas de rochas supracrustais, de natureza vulcano-sedimentar. Não existem definições para os limites do complexo. A área investigada neste trabalho (fig. 1) é limitada, a sul, pela Serra do Curral e, a norte, pelo Grupo Bambuí. Os limites a leste e oeste são balizados, respectivamente, pela Serra da Piedade e a cidade de Betim. Os litotipos típicos do Complexo Belo Horizonte estendem-se além destes limites, como demonstrado pelos estudos de Schorscher (1992) nos terrenos gnáissicos da região oriental do Quadrilátero Ferrífero. As características geoquímicas e petrográficas dos gnaisses regionais, descritos por Schorscher (1992), são indistintas daquelas das rochas gnáissico-migmatíticas que constituem o arcabouço do Complexo Belo Horizonte.

O litotipo amplamente dominante no Complexo Belo Horizonte é um gnaisse cinza-claro, frequentemente exibindo bandamento composicional e feições de migmatização. Esta rocha é referida, no presente trabalho, como Gnaisse Belo Horizonte. As características de campo desse gnaisse apontam para um caráter ortoderivado.

O Gnaisse Belo Horizonte apresenta feições bastante variáveis. $\mathrm{O}$ tipo mais frequente exibe fino bandamento, da ordem de milímetros a poucos centímetros, resultante da alternância de bandas leucocráticas e outras mais ricas em minerais máficos, essencialmente biotita. Localmente, as bandas atingem espessuras maiores, até $20-30 \mathrm{~cm}$. O bandamento pode apresentar caráter retilíneo e mais ou menos uniforme, ou encontrar-se fortemente dobrado e rompido. Observa-se uma gradação entre porções bandadas e outras de aspecto mais homogêneo, onde a estrutura dominante é uma foliação muito bem desenvolvida.

A intensidade dos fenômenos de migmatização varia de forma muito irregular dentro da área investigada. Nas exposições onde a migmatização do Gnaisse Belo Horizonte foi mais intensa, predominam estruturas do tipo schlieren ou estromática. Observam-se também estruturas do tipo schöllen e o desenvolvimento local de porções nebulíticas. $\mathrm{O}$ evento de migmatização foi datado por U-Pb em $2860+14 /-10 \mathrm{Ma}$ (Noce 1995).

A presença de encraves máficos é característica em algumas exposições do Gnaisse Belo Horizonte. A maior parte parece originar-se do rompimento de corpos tabulares concordantes com o bandamento. Apresentam formas irregulares e foram também afetados pela migmatização do gnaisse.

O Gnaisse Belo Horizonte é coitado por corpos intrusivos de natureza félsica. Na escala de afloramento, ocorrem veios granitóides, de grão fino a médio, pouco espessos, além de estreitos veios de pegmatito. Foram também identificados dois corpos graníticos (s.s.) circunscritos, de aspecto homogéneo e bem foliados, não afetados por migmatização. Ainda que relações de contato não tenham sido observadas, estes corpos foram interpretados como intrusivos no Gnaisse Belo Horizonte. Os plutonitos foram designados Granito Santa Luzia e Granito General Carneiro (Fig. 1). Um terceiro plutonito, exibindo feições de campo semelhantes aos supracitados mas composição granodiorítica, foi identificado nas proximidades de Ibirité (Fig. 1), Chemale Jr. et al. (1993) denominaram este corpo como Granodiorito Ibirité. O Granito Santa Luzia possui textura muito homogênea, caracterizado por apresentar fenocristais de feldspatos róseos orientados segundo a foliação, com até $2 \mathrm{~cm}$ de dimensão do eixo maior. A foliação é muito bem desenvolvida, mas não se observa qualquer bandamento. O Granito General Carneiro apresenta-se também bastante foliado, embora ocorram porções com textura porfirítica preservada.

Os corpos granitóides posicionaram-se após a migmatização do Gnaisse Belo Horizonte (ca. $2860 \mathrm{Ma}$ ), tendo sido afetados por pelo menos um evento deformacional anterior à tectônica principal do Supergrupo Minas (Evento Transamazônico). Idades de cristalização, por determinações U-Pb, são de 2712+5/-4 Ma para o Granito Santa Luzia (Noce 1995) e $2698 \pm 18$ Ma para o Granodiorito Ibirité (Chemale Jr. et al. 1993). Presume-se que o Granito General Carneiro tenha-se posicionado neste mesmo evento de granitogênese.

A presença de inclusões de rochas supracrustais com dimensões de poucos centímetros a vários quilómetros é uma feição característica dos complexos gnáissicos arqueanos (Condie 1981). No Complexo Belo Horizonte, ocorrem duas faixas vulcano-sedimentares com dimensões da ordem de 2-5 $\mathrm{km}$, orientadas segundo N-S e apresentando mergulhos elevados. Constituem-se de anfibolitos, formação ferrífera, quartzitos e quartzo-mica xistos. O Granito General Carneiro é, provavelmente, intrusivo em uma dessas faixas, a qual é cortada por corpos pegmatíticos próximo ao contato com o granito.

Petroquímica As amostras foram analisadas nos laboratórios da Geologia e Sondagens S.A. (Geosol), com exceçao daquelas de numeração N-59, N-67, N-69 e N-71, que foram analisadas no Centro de Pesquisa Prof. Manoel Teixeira da Costa (CPMTC). A rotina da Geosol consiste em utilizar a Fluorescência de Raios X para determinar os elementos maiores e traços, enquanto os elementos terras raras são analisados por Espectrometria de Plasma-ICP. No CPMTC todos os elementos foram analisados no ICP, exceto $\mathrm{Na}, \mathrm{K}$ e $\mathrm{Fe}^{2+}$. O último foi determinado por via úmida e os demais por fotometria de chama.

GNAISSE BELO HORIZONTE O estudo petrográfico do Gnaisse Belo Horizonte mostra uma relação plagioclásio/ K-feldspato bastante variável, resultando na presença de termos tonalíticos até graníticos, com expressiva predominância dos primeiros. Nos termos tonalíticos, o K-feldspato possui caráter intersticial, enquanto nas rochas granodioríticas a graníticas pode formar megacristais geralmente pertíticos e ricos em inclusões, predominantemente de plagioclásio. O plagioclásio, em geral oligoclásio, está quase sempre saussuritizado e alguns cristais exibem zonamento. A biotita é sempre o mineral máfico principal, perfazendo em média 5 a $10 \%$ da rocha. Via de regra, apresenta alteração para clorita e/ou mica branca. Anfibólio (hornblenda) pode estar presente em algumas amostras, de forma muito subordinada. Os accessórios mais comuns são titanita, epidoto, apatita e zircão. Allanita está presente nas rochas de composição granítica. Algumas amostras ainda preservam texturas ígneas, em geral inequigranular hipidiomórfica a xenomórfica. Nas demais, a textura é granoblástica ou milonítica.

Foram efetuadas 7 análises químicas completas, incluindo elementos terras raras, para o Gnaisse Belo Horizonte. Outras três análises de elementos maiores e menores provêm de Herz (1970). Como norma, amostraram-se exposições onde a migmatização mostrava-se incipiente, ou porções que pareciam mais preservadas deste processo. Para efeito de comparação, foram feitas análises do gnaisse migmatítico. Os dados das análises químicas estão apresentados na Tabela 1. As análises 1 a 8 representam os gnaisses discretamente migmatizados ou sem evidência de migmatização. Sua composição química é trondhjemítica, enquanto os gnaisses migmatíticos (análises 9 e 10) apresentam composição granítica (Fig. 2). Nestes casos, o material analisado representa uma mistura de neossoma e paleossoma, dado à impossibilidade de separação na amostragem.

Com base nos parâmetros de Shand $\left[\mathrm{Al}_{2} \mathrm{O}_{3} \mathrm{~mol} /\right.$ $\left(\mathrm{Na}_{2} \mathrm{O}+\mathrm{K}_{2} \mathrm{O}+\mathrm{CaO}\right)$ mol], seis amostras do Gnaisse Belo Horizonte (análises 1,2,3,6,7 e 8, Tabela 1) apresentam caráter peraluminoso, enquanto duas (análises 4 e 5 , Tabela 1) são metaluminosas (Fig. 3). O gnaisse possui teores elevados em 


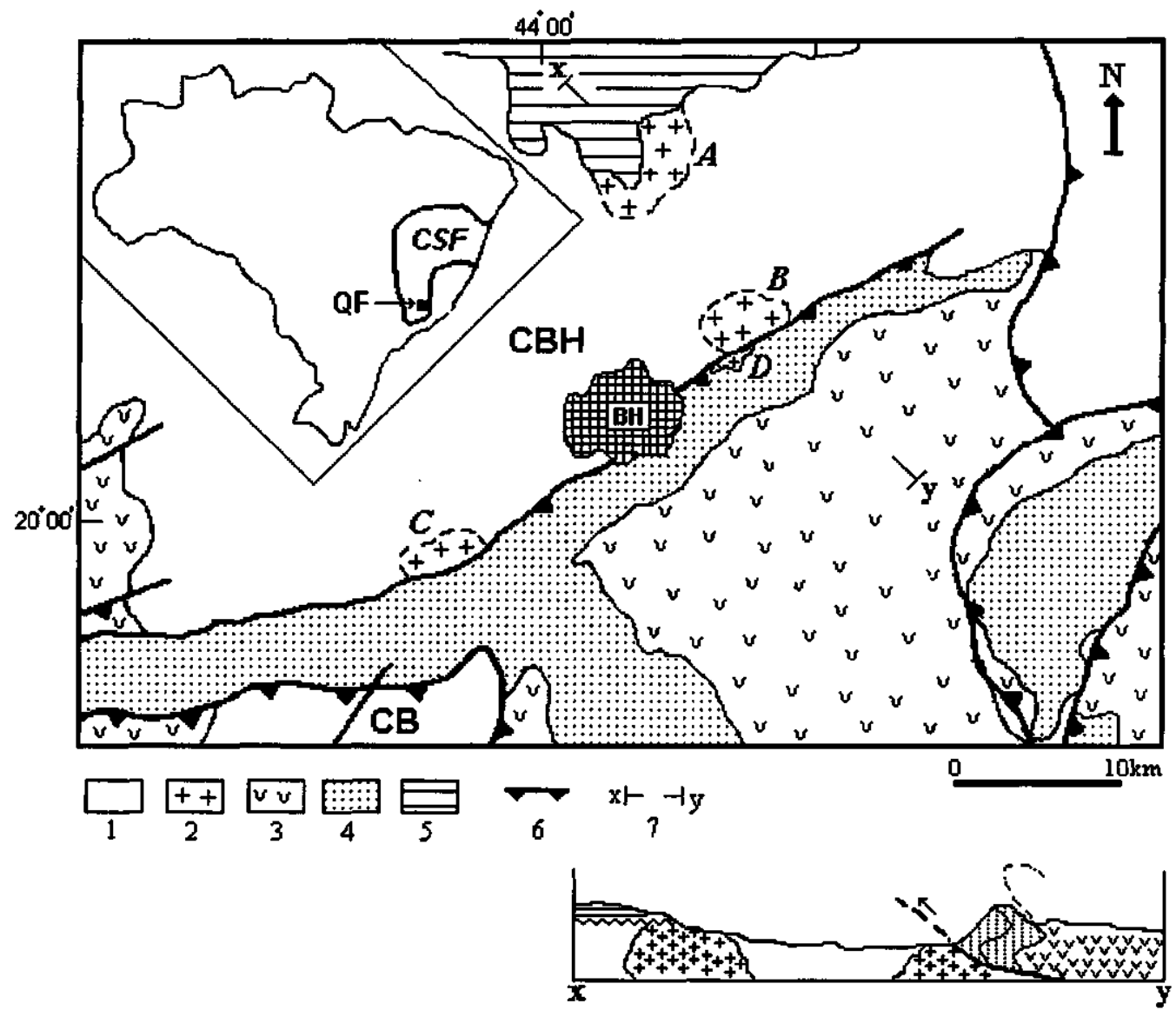

Figura 1 - Mapa geológico simplificado da região norte do Quadrilátero Ferrífero. 1. Gnaisses TTG; 2. Granitóides neoarqueanos (A. Granito Santa Luzia; B. Granito General Carneiro; C. Granodiorito Ibirité, D. Granito Marzagão); 3. Greenstone Belt Rio das Velhas; 4. Supergrupo Minas; 5. Grupo Bambuí. 6. falha de empurrão; 7. perfil geológico. CEE. Complexo Belo Horizonte; CB. Complexo Bonfim; CSF. Cráton do São Francisco; QF. Quadrilátero Ferrífero; BH. cidade de Belo Horizonte. Figure 1 - Simplified geological map of northern Quadrilátero Ferrífero. 1. TTG gneisses; 2. Neoarchean granitoids (A. Santa Luzia granite; B. General Carneiro granite; C. Ibirité granodiorite; D. Marzagão granite); 3. Rio das Velhas greenstone belt; 4. Minas supergroup; 5. Bambuí group; 6. thrust fault; 7. geological section. CBH. Belo Horizonte complex; CB. Bonfim complex; CSF. São Francisco craton; QF. Quadrilátero Ferrífero; BH. Belo Horizonte city.

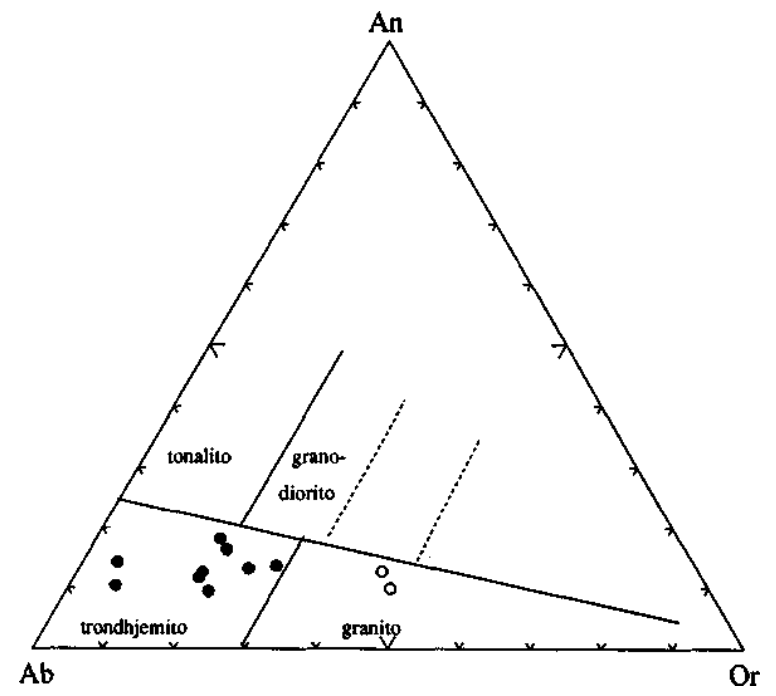

$\mathrm{Na}_{2} \mathrm{O}$ (média de 5,2). Os teores em $\mathrm{Na}_{2} \mathrm{O}$ e $\mathrm{K}_{2} \mathrm{O}$ variam consideravelmente e a razão $\mathrm{K}_{2} \mathrm{O} / \mathrm{Na}_{2} \mathrm{O}$ apresenta espectro amplo, entre 0,21 e 0,78, com média de 0,46. Os teores em $\mathrm{SiO}_{2}$ são relativamente elevados (média de 72,5\%). O CaO varia pouco, entre 1,5 e $2,3 \%$. No conjunto, esses valores aproximam-se daqueles atribuídos aos trondhjemitos por Barker (1979), quais sejam: $\mathrm{SiO}_{2}>68 \%, \mathrm{Fe}_{2} \mathrm{O}_{3}+\mathrm{MgO}<3,4 \%$, $\mathrm{Na}_{2} \mathrm{O}$ entre $4,0-5,5 \%$ e $\mathrm{K}_{2} \mathrm{O}<2 \%$.

A figura 4 apresenta alguns diagramas de variação geoquímica utilizando o índice de diferenciação (ID) de Thornton \& Tuttle (1969). Este tipo de estudo fica prejudicado pelo número pouco expressivo de análises e, possivelmente, pelo caráter polimetamórfico do gnaisse, o que poderia ter induzido a mobilidade de certos elementos maiores e traços. Foram selecionados apenas os diagramas onde o comportamento do elemento define algum tipo de trend. As amostras com maior índice de diferenciação são aquelas cujo estudo petrográfico revelou conteúdo mais elevado em K-feldspato, indicando composição granodiorítica (análises 1,2,3 e 5, Tabela 1). Estes termos mais diferenciados mostram enriquecimento em Figura 2 - Composição do Gnaisse Belo Horizonte (círculos $\mathrm{SiO}_{2}$ e empobrecimento em $\mathrm{TiO}_{2}, \mathrm{MgO} \mathrm{Fe}_{2} \mathrm{O}_{3}+\mathrm{FeO}, \mathrm{CaO}$ e preenchidos) e gnaisse migmatítico (círculos vazios) no dia-Sr. Por exemplo, o caráter compatível do Ca e $\mathrm{Sr}$ poderia ser grama normativo Ab-An-Or de O'Connor (1965). explicado pela cristalização do plagioclásio durante a evoFigure 2 - Belo Horizonte gneiss (filled circles) and migmatitic gneiss (open lução do processo magmático. Entretanto, é importante assicircles) compositions in the normative Ab-An-Or diagram from O'Connor nalar que estes trenas de diferenciação magmática são defini(1965).

dos nos diagramas de forma pouco consistente, dado a dis- 
Tabela 1 - Composição química do Gnaisse Belo Horizonte (análises 1 a 8) e gnaisse migmatítico (análises 9 e 10). Table 1 - Chemical composition of the Belo Horizonte gneiss (analysis 1 to 8) and migmatitic gneiss (analysis 9 and 10).

\begin{tabular}{|c|c|c|c|c|c|c|c|c|c|c|}
\hline $\begin{array}{l}\text { Número } \\
\text { Amostra }\end{array}$ & $\begin{array}{c}1 * \\
\mathbf{A 6 5 3} \\
\end{array}$ & $\begin{array}{c}2 * \\
\text { Ha-140 }\end{array}$ & $\begin{array}{c}3 \\
\text { N-38A }\end{array}$ & $\begin{array}{c}4 \\
N-37 A\end{array}$ & $\begin{array}{c}5 \\
N-69 \\
\end{array}$ & $\begin{array}{c}6 \\
N-71 \\
\end{array}$ & $\begin{array}{c}7 \\
N-67 \\
\end{array}$ & $\begin{array}{c}8 \\
\text { N-59 } \\
\end{array}$ & $\begin{array}{r}9 \\
\mathrm{~N}-\mathbf{3 3 A} \\
\end{array}$ & $\begin{array}{c}10^{*} \\
\text { Ha-16a }\end{array}$ \\
\hline $\mathrm{SiO}_{2}$ & 73,6 & 73,5 & 73,4 & 72,4 & 72,1 & 70,2 & 69,8 & 69,6 & 70,7 & 69,4 \\
\hline $\mathrm{TiO}_{2}$ & 0,19 & 0,19 & 0,21 & 0,29 & 0,19 & 0,35 & 0,30 & 0,40 & 0,43 & 0,48 \\
\hline $\mathrm{Al}_{2} \mathrm{O}_{3}$ & 14,8 & 14,9 & 14,5 & 13,9 & 14,1 & 15,7 & 15,7 & 15,5 & 14,1 & 14,6 \\
\hline $\mathrm{Fe}_{2} \mathrm{O}_{3}$ & 0,10 & 0,50 & 0,37 & 1,20 & 0,36 & 0,43 & 0,57 & 0,57 & 1,70 & 0,80 \\
\hline $\mathrm{FeO}$ & 1,4 & 1,2 & 1,2 & 1,1 & 1,18 & 2,3 & 1,75 & 1,8 & 1,1 & 2,0 \\
\hline $\mathrm{MnO}$ & 0,04 & 0,05 & 0,02 & 0,04 & 0,02 & 0,03 & 0,03 & 0,03 & 0,04 & 0,08 \\
\hline $\mathrm{MgO}$ & 0,38 & 0,44 & 0,39 & 0,74 & 0,51 & 0,88 & 0,76 & 1,13 & 0,68 & 0,68 \\
\hline $\mathrm{CaO}$ & 1,5 & 1,7 & 1,8 & 2,3 & 1,6 & 2,0 & 1,5 & 2,2 & 1,7 & 2,1 \\
\hline $\mathrm{Na}_{2} \mathrm{O}$ & 5,1 & 4,9 & 4,0 & 4,5 & 5,4 & 6,4 & 6,6 & 4,7 & 3,3 & 3,2 \\
\hline $\mathrm{K}_{2} \mathrm{O}$ & 2,3 & 2,2 & 3,1 & 2,2 & 2,5 & 1,4 & 1,4 & 2,9 & 5,2 & 5,1 \\
\hline $\mathrm{P}_{2} \mathrm{O}_{5}$ & 0,04 & 0,08 & 0,06 & 0,10 & 0,07 & 0,05 & 0,06 & 0,12 & 0,14 & 0,26 \\
\hline $\mathrm{H}_{2} \mathrm{O}^{+}$ & 0,52 & 0,54 & 0,69 & - & 0,53 & 0,60 & 0,97 & 0,89 & 0,50 & 0,58 \\
\hline $\mathrm{CO}_{2}$ & $\cdot$ & 0,06 & 0,10 & - & $\cdot$ & - & - & - & 0,20 & 0,14 \\
\hline $\mathrm{PF}$ & & & & 0,90 & & & & & & \\
\hline total & 99,97 & 100,26 & 99,84 & 99,67 & 98,56 & 100,34 & 99,44 & 99,84 & 99,79 & 99,42 \\
\hline $\mathrm{K}_{2} \mathrm{O} / \mathrm{Na}_{2} \mathrm{O}$ & 0,45 & 0,45 & 0,78 & 0,49 & 0,46 & 0,22 & 0,21 & 0,62 & 1,58 & 1,59 \\
\hline $\mathrm{V}$ & 12 & 26 & 78 & 29 & $<10$ & 17 & 13 & 25 & 122 & 21 \\
\hline $\mathrm{Pb}$ & 19 & 32 & 8 & 37 & 54 & 54 & 40 & 49 & 12 & 15 \\
\hline $\mathrm{Rb}$ & - & - & 98 & 110 & - & - & - & - & 150 & - \\
\hline $\mathrm{Ba}$ & 800 & 440 & 820 & 600 & 1427 & 1055 & 1120 & 2175 & 970 & 1600 \\
\hline $\mathrm{Sr}$ & 230 & 240 & 290 & 490 & 305 & 317 & 414 & 365 & 330 & 380 \\
\hline $\mathrm{Nb}$ & 22 & 13 & $<8$ & - & - & - & - & - & 18 & 27 \\
\hline $\mathrm{Zr}$ & 140 & 106 & 140 & 250 & - & - & - & - & 220 & 310 \\
\hline $\mathrm{Y}$ & 15 & 13 & 17 & 24 & 6 & 7 & 7 & 18 & 47 & 66 \\
\hline $\mathrm{La}$ & & & 24,13 & 24,93 & 23,7 & 19,8 & 21,3 & 23,9 & 83,5 & \\
\hline $\mathrm{Ce}$ & & & 55,21 & 52,73 & 44,9 & 39,3 & 40,1 & 59,7 & 178,5 & \\
\hline Nd & & & 18,03 & 18,78 & 16,0 & 14,3 & 15,6 & 21,0 & 68,93 & \\
\hline $\mathrm{Sm}$ & & & 4,034 & 3,441 & 2,6 & 2,5 & 2,7 & 4,0 & 14,63 & \\
\hline $\mathrm{Eu}$ & & & 0,506 & 0,558 & 0,64 & 0,59 & 0,65 & 0,88 & 1,448 & \\
\hline $\mathrm{Gd}$ & & & 2,363 & 2,342 & 2,4 & 2,5 & 2,5 & 3,9 & 8,873 & \\
\hline Dy & & & 2,055 & 1,78 & 1,1 & 1,4 & 1,6 & 3,3 & 7,707 & \\
\hline Ho & & & 0,405 & 0,349 & 0,20 & 0,24 & 0,25 & 0,64 & 1,437 & \\
\hline $\mathrm{Er}$ & & & 1,073 & 0,915 & 0,59 & 0,69 & 0,64 & 1,8 & 3,361 & \\
\hline $\mathrm{Yb}$ & & & 0,896 & 0,626 & 0,51 & 0,57 & 0,44 & 1,5 & 2,021 & \\
\hline Lu & & & 0,117 & 0,10 & 0,07 & 0,08 & 0,05 & 0,18 & 0,228 & \\
\hline$(\mathrm{La} / \mathrm{Sm}) \mathrm{n}$ & & & 3,77 & 4,56 & 5,74 & 4,99 & 4,98 & 3,76 & 3,59 & \\
\hline$(\mathrm{Gd} / \mathrm{Yb}) \mathrm{n}$ & & & 2,13 & 3,02 & 3,80 & 3,54 & 4,59 & 2,10 & 3,55 & \\
\hline (Eu)n/Eu* & & & 0,46 & 0,57 & 0,77 & 0,71 & 0,75 & 0,67 & 0,36 & \\
\hline
\end{tabular}

* extraído de HERZ, 1970

persão dos pontos analíticos. Desta forma, não é possível afirmar que as amostras pertençam a uma única série magmática ou que, alternativamente, os termos tonalíticos menos diferenciados e os termos granodioríticos mais diferenciados pertençam a séries distintas. O comportamento dos elementos terras raras não fornece subsídios para esclarecer esta questão, na medida em que o conjunto de amostras mais diferenciadas não possui um comportamento distinto das demais (Tabela 1). Em um diagrama de distribuição de elementos incompatíveis, para duas amostras do Gnaisse Belo Horizonte (Fig. 5), pode-se destacar a ausência de anomalias de $\mathrm{Sr}$ e Ba e a forte anomalia negativa de $\mathrm{Nb}$ e $\mathrm{Ti}$. As curvas de elementos terras raras (Fig. 6) revelam acentuado empobrecimento em elementos terras raras pesadas e fraca anomalia negativa de
Eu. O comportamento dos elementos terras raras leves é bastante constante para o conjunto de análises, o mesmo não ocorrendo com os elementos terras raras pesadas. A razão $(\mathrm{La} / \mathrm{Sm}) \mathrm{N}$ varia entre 3,8 e 5,7 e a razão $(\mathrm{Gd} / \mathrm{Yb}) \mathrm{N}$ entre 2.1 e 4.6.

As análises do gnaisse migmatítico (análises 9 e 10, Tabela 1) mostram enriquecimento em $\mathrm{K}_{2} \mathrm{O}$ e teores mais baixos em $\mathrm{Na}_{2} \mathrm{O}$, sendo a razão $\mathrm{K}_{2} \mathrm{O} / \mathrm{Na}_{2} \mathrm{O}$ maior que 1 . $\mathrm{O}$ espectro de elementos terras raras para uma das amostras (análise 9, Tabela 1), quando comparada com as curvas do gnaisse pouco migmatizado, exibe enriquecimento generalizado nos elementos terras raras e anomalia negativa de Eu mais acentuada (Fig. 6), porém revela forma e inclinação semelhantes. Outro fator distintivo é o acentuado empobrecimento em $\mathrm{Sr}$ em 


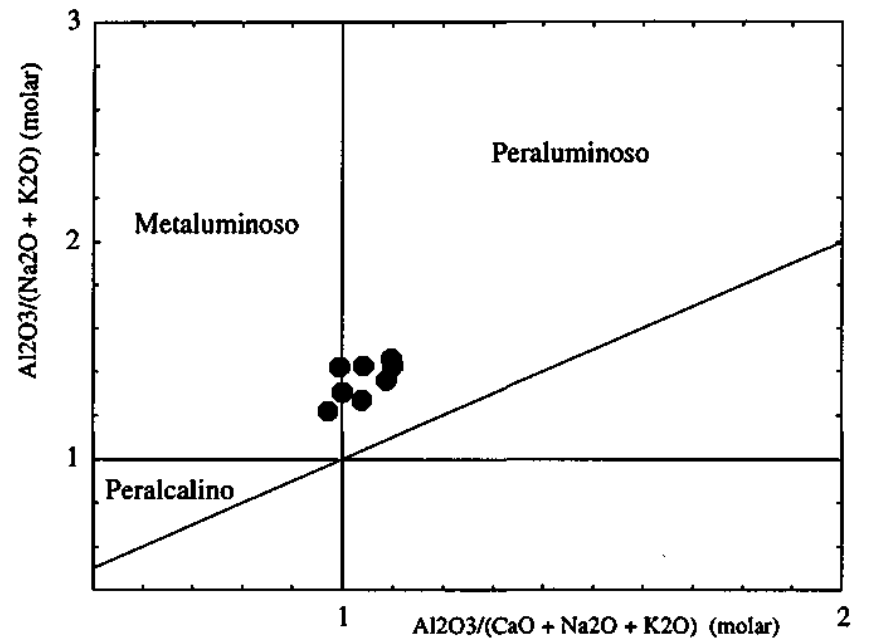

Figura 3 - Diagrama de saturação de alumínio para o Gnaisse Belo Horizonte (segundo Maniar \& Piccoli 1989).

Figure 3 - Alumina saturation diagram for the Belo Horizonte gneiss (after Maniar \& Piccoli 1989).
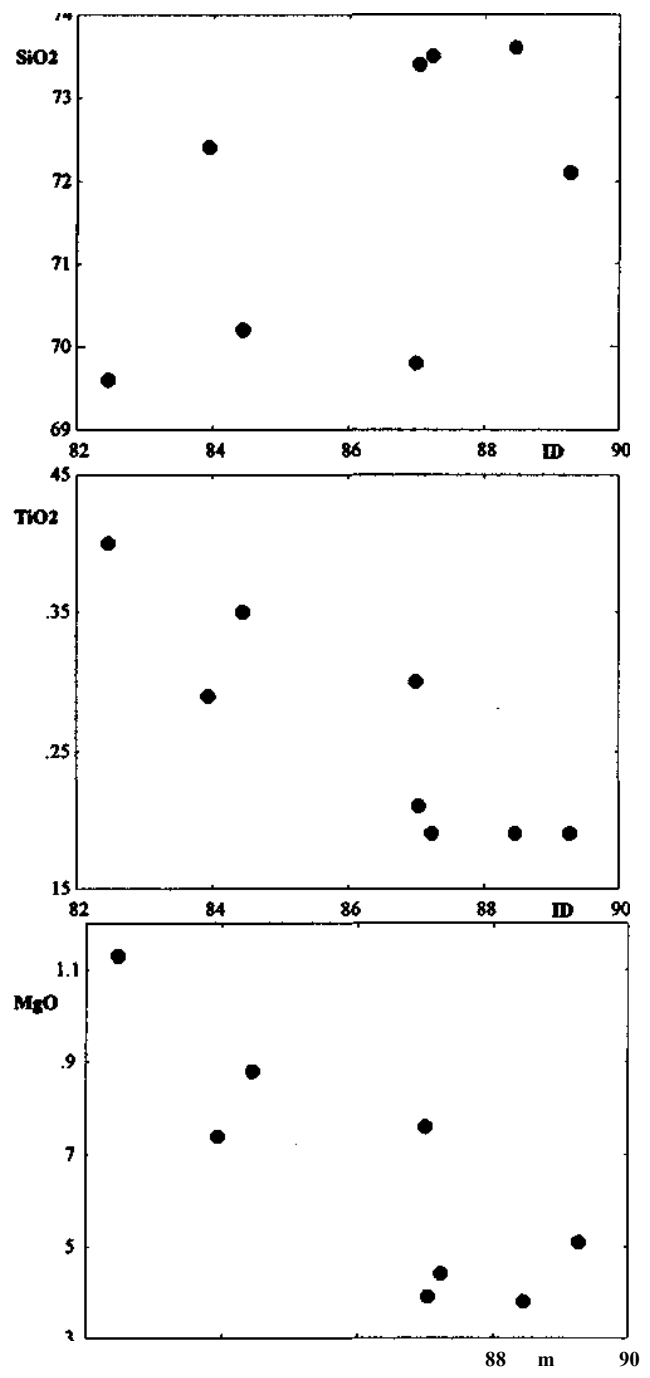

relação a elementos de similar "compatibilidade", presente apenas no gnaisse migmatítico (Fig. 5). A anomalia negativa de Eu mais acentuada, juntamente com a de Sr, podem ser explicadas como uma função do fracionamento de plagioclásio. Os espectros de elementos terras raras e spidergrams do gnaisse migmatítico e do Gnaisse Belo Horizonte sugerem que o primeiro pode realmente resultar de fusão parcial do segundo. Plagioclásio e zircão, sendo mais refratários, ficariam na fonte.

Condie (1981) apresenta composições químicas médias para tonalitos e trondhjemitos arqueanos, divididos segundo a classificação de Barker (1979) em alto $\mathrm{Al}_{2} \mathrm{O}_{3}$ e baixo $\mathrm{Al}_{2} \mathrm{O}_{3}$. A figura 7 exibe as curvas de elementos terras raras para as duas classes, comparadas com a curva média para o Gnaisse Belo Horizonte. Constata-se marcante semelhança entre esta última e a curva dos tonalitos e trondhjemitos de alto $\mathrm{Al}_{2} \mathrm{O}_{3}$, exceto pela anomalia negativa de $\mathrm{Eu}$ presente no Gnaisse Belo Horizonte. Entretanto, em termos de elementos maiores, as amostras do gnaisse posicionam-se nas duas classes de tronhdjemitos (alto e baixo $\mathrm{Al}_{2} \mathrm{O}_{3}$ ). Outra comparação é feita com a curva média de elementos terras raras para o Gnaisse Alberto Flores (Fig. 7), que representa a crosta continental mais antiga do Complexo Bonfim (Carneiro 1992). A
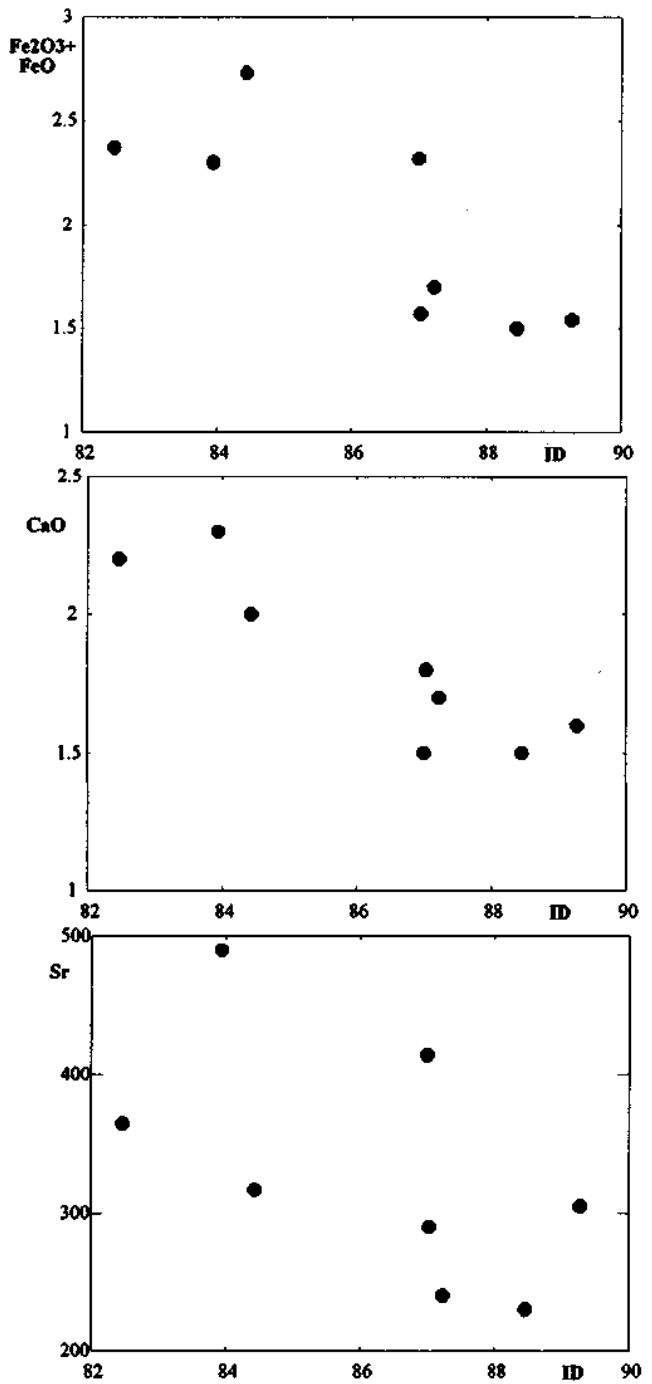

Figura 4 - Diagramas de variação de elementos maiores e traço em relação ao índice de diferenciação (ID) de Thornton \& Tuttle (1969), para o Gnaisse Belo Horizonte.

Figure 4 - Variation diagrams for major and trace elements versus the differentiation index after Thornton \& Tuttle (1969), for the Belo Horizonte gneiss. 


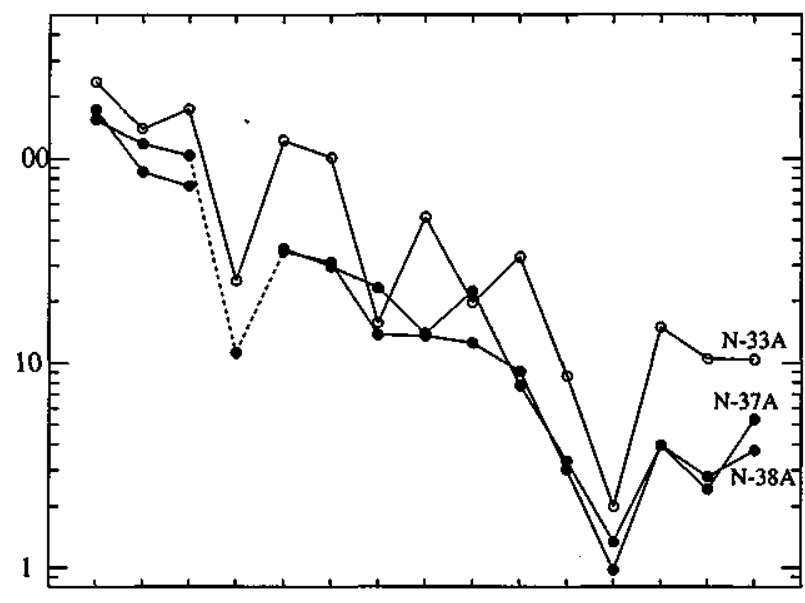

$\mathrm{Rb} \mathrm{Ba} K \mathrm{Nb}$ La Ce Sr Nd Zr Sm Eu Ti Gd Dy Y

Figura 5 - Distribuição dos elementos incompativeis para amostras do Gnaisse Belo Horizonte (círculos preenchidos) e gnaisse migmatítico (círculos vazios), normalizados ao manto primitivo (valores de normalização de Sun \& McDonough 1989).

Figure 5 - Distribution of incompatible elements of samples from the Belo Horizonte gneiss (filled circles) and migmatitic gneiss (open circles) normalized to primitive mantle (norm values from Sun \& McDonough 1989).

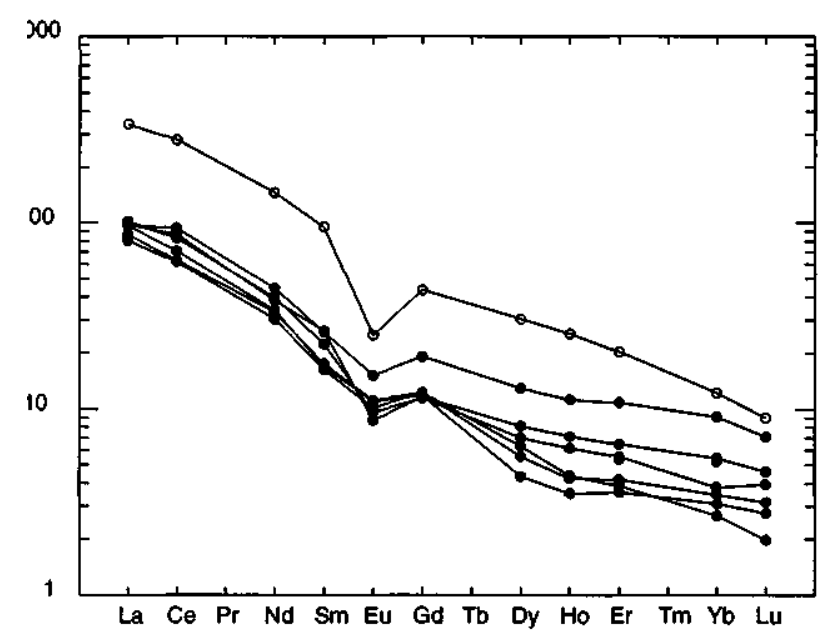

Figura 6 - Curvas de elementos terras raras, normalizadas aos condritos (valores de normalização de Evensen et ai. 1978), para o Gnaisse Belo Horizonte (circulos preenchidos) e gnaisse migmatítico (círculos vazios).

Figure 6 - Chondrite-normalized REE patterns (norm values from Evensen et ai. 1978) for the Belo Horizonte gneiss (filled circles) and migmatitic gneiss (open circles).

anomalia de Eu é mais acentuada no Gnaisse Alberto Flores que no Gnaisse Belo Horizonte.

GRANITÓIDES NEOARQUEANOS O Granito Santa Luzia encontra-se bastante deformado, exibindo textura granoblástica. O K-feldspato ocorre em proporção mais elevada que o plagioclásio, formando megacristais róseos. Quartzo e biotita completam a mineralogia essencial. O plagioclásio apresenta-se profundamente saussuritizado. Titanita é um acessório frequente, ocorrendo como mineral primário e também como produto subordinado associado à cloritização da biotita. Deve-se ressaltar a presença de allanita, que chega a formar cristais euédricos com até $3 \mathrm{~mm}$ de dimensão.

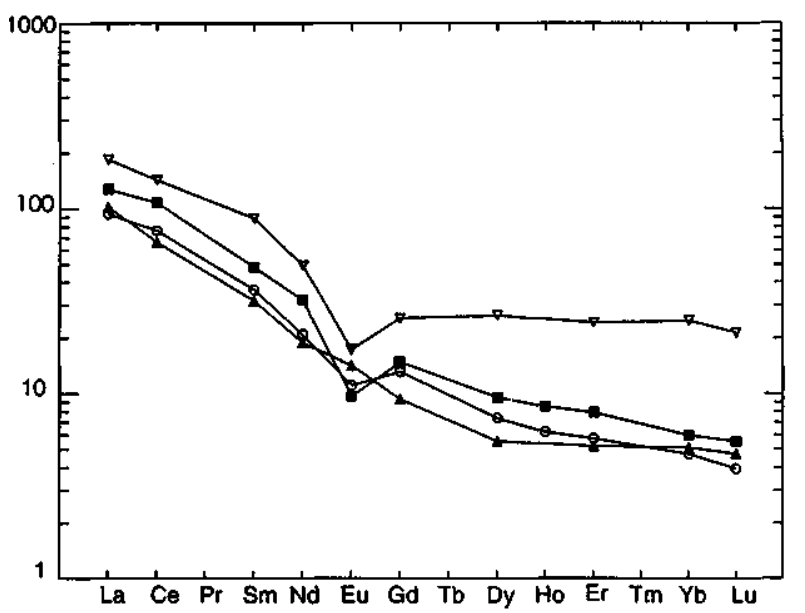

Figura 7 - Curvas de elementos terras raras, normalizadas aos condritos (valores de normalização de Evensen et ai. 1978), para o Gnaisse Belo Horizonte (círculos vazios), Gnaisse Alberto Flores (quadrados preenchidos; Carneiro 1992), tonalitos/trondhjemitos arqueanos de alto Al (triângulos preenchidos) e baixo Al (triângulos vazios; Condie 1981). Figure 7 - Chondrite-normalized REE patterns (norm values from Evensen et al. 1978) for the Belo Horizonte gneiss (open circles), Alberto Flores (filled squares; Carneiro 1992), high-Al (filled triangles) and low-Al (open triangles) Archean tonalite-trondhjemite (Condie 1981).

O Granito General Carneiro possui cor cinza-clara e é constituído por quartzo, K-feldspato e plagioclásio em proporções semelhantes. $\mathrm{O}$ mineral máfico é biotita, perfazendo menos que $5 \%$ da rocha. O K-feldspato pode formar megacristais de ortoclásio, pertíticos e ricos em inclusões, o que confere à rocha um caráter porfirítico. Ocorre também na matriz como grãos menores e mais límpidos de microclina. Estes cristais sofreram alguma recristalização, tendendo a formar bandas de textura granoblástica. A biotita apresenta-se quase totalmente alterada para mica branca e clorita. Este material micáceo, acrescido daquele proveniente da alteração do plagioclásio, orienta-se em faixas definindo a foliação. Assinala-se a presença esporádica de granada como mineral accessório.

Os dois corpos intrusivos em causa são granitos cálcioalcalinos ricos em potássio. Com base nos parâmetros de Shand $\left[\mathrm{Al}_{2} \mathrm{O}_{3} \mathrm{~mol} /\left(\mathrm{Na}_{2} \mathrm{O}+\mathrm{K}_{2} \mathrm{O}+\mathrm{CaO}\right)\right.$ mol são classificados como peraluminosos, embora uma das amostras do Granito Santa Luzia (análise 2, tabela 2) seja ligeiramente metaluminosa. O Granito Santa Luzia possui conteúdo em $\mathrm{SiO}_{2}(68 \%)$ consideravelmente menor que o do Granito General Carneiro (74\%), ao contrário do que acontece com o conteúdo em $\mathrm{FeO}(\mathrm{t})+\mathrm{MgO}$, mais elevado no primeiro. Valores de $\mathrm{CaO}$ são mais elevados para o Granito Santa Luzia, como também as razões $\mathrm{K}_{2} \mathrm{O} / \mathrm{Na}_{2} \mathrm{O}$ (1,9 no Granito Santa Luzia e 1,1-1,4 no Granito General Carneiro).

Os teores de $\mathrm{Rb}$ são maiores para o Granito General Carneiro, mas o oposto acontece em relação ao $\mathrm{Sr}$, com teores em torno de 500 ppm no Granito Santa Luzia e 150 ppm no Granito General Carneiro. Os teores de Ba são, igualmente, bem mais elevados no Granito Santa Luzia. A despeito destas diferenças, em um diagrama normalizado de distribuição de elementos incompatíveis, as curvas dos dois corpos são semelhantes (Fig. 8). Estas exibem característica depressão em Sr, além de $\mathrm{Nb}$ e Ti. A depressão em $\mathrm{Nb}$ é, proporcionalmente, mais pronunciada no Granito Santa Luzia.

As curvas de elementos terras raras dos dois granitos são distintas (Fig. 9). O Granito Santa Luzia é mais enriquecido em elementos terras raras e apresenta fracionamento acentuado, com razão $(\mathrm{La} / \mathrm{Yb}) \mathrm{N}=19,2$. O fracionamento no Gra- 


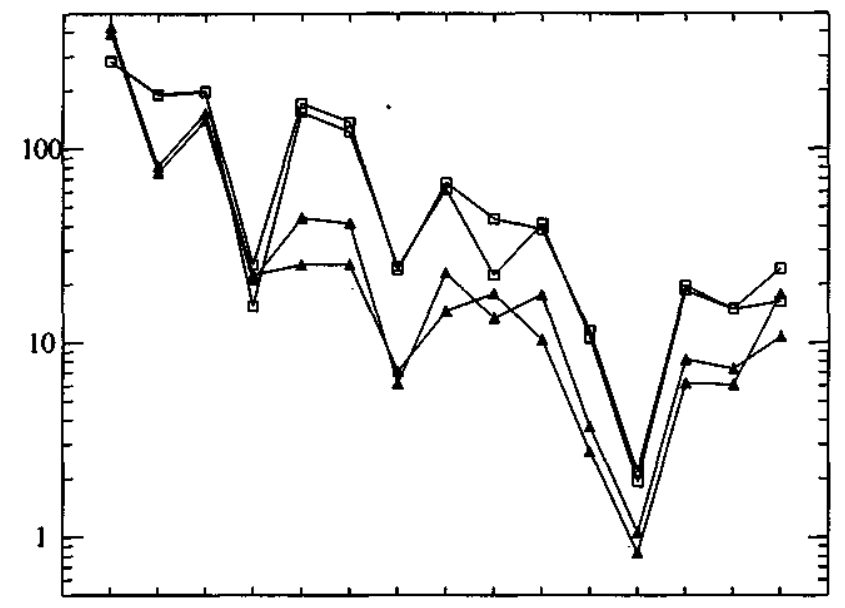

Rb Ba K Nb La Ce Sr Nd Zr Sm Eu Ti Gd Dy Y

Figura 8 - Distribuição dos elementos incompatíveis para amostras do Granito Santa Luzia (quadrados vazios) e Granito General Carneiro (triângulos preenchidos), normalizados ao manto primitivo (valores de normalização de Sun \& McDonough 1989).

Figure 8 - Distribution of incompatible elements of samples from the Santa Luzia granite (open squares) and General Carneiro granite (filled triangles) normalized to primitive mantle (norm values from Sun \& McDonough 1989).

nito General Carneiro é bem menos acentuado, exibindo razão $(\mathrm{La} / \mathrm{Yb}) \mathrm{N}=5,8$. A anomalia de Eu difere pouco de um corpo para outro. Estas curvas, especialmente do Granito General Carneiro, são bem mais típicas de granitóides mais evoluídos, de derivação crustal (e.g. Grossi Sad \& Dutra 1989). Os teores mais altos em elementos terras raras no Granito Santa Luzia poderiam ser explicados pela presença de allanita.

Os granitos General Carneiro e Marzagão (Gair 1962) ocorrem lado a lado, porém sem relações de campo observáveis. $\mathrm{O}$ Granito Marzagão é bem mais pobre em minerais máficos e encontra-se fortemente cisalhado. Em termos de composição química em relação ao Granito General Carneiro, é mais pobre em $\mathrm{FeO}(\mathrm{t})$ e $\mathrm{TiO}_{2}$, e muito mais rico em $\mathrm{Al}_{2} \mathrm{O}_{3}$ (Tabela 2). As diferenças entre os dois granitos poderiam ser explicadas por processos metassomáticos associados à milonitização. Neste caso, é possível que o Granito Marzagão constituía uma faixa milonitizada do Granito General Carneiro.

O Granodiorito Ibirité possui apenas uma análise química disponível (Tabela 2). Sua curva de elementos terras raras encontra-se na figura 9. Em relação aos demais granitóides, o Granodiorito Ibirité apresenta-se mais empobrecido em elementos terras raras e exibe anomalia negativa de Eu menos acentuada.

CONCLUSÕES A despeito das transformações sofridas em função de eventos de retrabalhamento, a assinatura geoquímica do Gnaisse Belo Horizonte ainda reflete sua identificação com as suítes TTG do Arqueano. A gênese dessas suítes tem sido objeto de considerável debate, especialmente por estar relacionada à própria origem primária da crosta continental. Segundo Tarney \& Saunders (1990), é geralmente aceito que certas características geoquímicas das suítes TTG arqueanas (fracionamento acentuado dos elementos terras raras e empobrecimento em elementos terras raras pesadas; marcante anomalia de $\mathrm{Nb}$; ausência de anomalias ou anomalias positivas de $\mathrm{Eu}, \mathrm{Sr}$ e Ba; baixos teores de $\mathrm{Th}, \mathrm{U}$ e $\mathrm{Rb}$; razão $\mathrm{K} / \mathrm{Rb}$ elevada) podem ser explicadas pela fusão parcial de uma fonte anfibolítica ou granada-anfibolítica. Tal
Tabela 2 - Composição química do Granito Santa Luzia (análises 1 e 2), Granito General Carneiro (análises 3 e 4), Granodiorito Ibirité (análise 5) e Granito Marzagão (análise 6).

Table 2 - Chemical composition of the Santa Luzia granite (analysis 1 and 2), General Carneiro granite (analysis 3 and 4), Ibirité granodiorite (analysis 5) and Marzagão granite (analysis 6).

\begin{tabular}{|c|c|c|c|c|c|c|}
\hline \multirow[b]{2}{*}{$\begin{array}{l}\text { Número } \\
\text { Amostra }\end{array}$} & \multicolumn{2}{|c|}{$\delta$ Santa Luzia } & \multicolumn{2}{|c|}{$\delta$ Gen. Carneiro } & \multirow{2}{*}{\begin{tabular}{|c|}
$\delta$ Ibirité \\
$\mathbf{5}$ \\
$\mathbf{N}-39$
\end{tabular}} & \multirow{2}{*}{\begin{tabular}{|c}
$\delta$ Marzagāo \\
6 \\
JG.105*
\end{tabular}} \\
\hline & $\begin{array}{c}1 \\
\text { N.57A }\end{array}$ & $\begin{array}{c}2 \\
\text { N-57B }\end{array}$ & $\stackrel{3}{N-41}$ & $\begin{array}{c}4 \\
N \cdot 42\end{array}$ & & \\
\hline $\mathrm{SiO}_{2}$ & 67,8 & 68,0 & 74,3 & 74,0 & 75,7 & 72,2 \\
\hline $\mathrm{TiO}_{2}$ & 0,42 & 0,47 & 0,18 & 0,23 & 0,19 & 0,08 \\
\hline $\mathrm{Al}_{2} \mathrm{O}_{3}$ & 15,2 & 14,8 & 13,4 & 13,9 & 12,6 & 16,0 \\
\hline $\mathrm{Fe}_{2} \mathrm{O}_{3}$ & 1,80 & 1,40 & 0,61 & 0,61 & 0,39 & 0,30 \\
\hline $\mathrm{FeO}$ & 1,40 & 1,50 & 0,89 & 0,98 & 1,0 & 0,88 \\
\hline $\mathrm{MnO}$ & 0,06 & 0,05 & 0,05 & 0,04 & 0,04 & 0,02 \\
\hline $\mathrm{MgO}$ & 1,00 & 1,00 & 0,47 & 0.41 & 0,56 & 0,34 \\
\hline $\mathrm{CaO}$ & 1,7 & 1,9 & 0,98 & 1,10 & 1,5 & 0,62 \\
\hline $\mathrm{Na}_{2} \mathrm{O}$ & 3,1 & 3,1 & 3,2 & 3,7 & 4,0 & 3,3 \\
\hline $\mathrm{K}_{2} \mathrm{O}$ & 6,0 & 5,9 & 4,6 & 4,2 & 2,6 & 5,2 \\
\hline $\mathrm{P}_{2} \mathrm{O}_{5}$ & 0,18 & 0,23 & 0,08 & 0,09 & 0,05 & 0,12 \\
\hline $\mathrm{H}_{2} \mathrm{O}^{+}$ & 0,83 & - & - & 0,48 & - & 0,84 \\
\hline $\mathrm{CO}_{2}$ & 0,25 & - & - & 0,15 & - & - \\
\hline $\mathrm{PF}$ & & 1,33 & 1,02 & & 1,10 & \\
\hline total & 99,74 & 99,68 & 99,78 & 99,89 & 99,73 & 99,90 \\
\hline $\mathrm{K}_{2} \mathrm{O} / \mathrm{Na}_{2} \mathrm{O}$ & 1,94 & 1,90 & 1,44 & 1,14 & 0,65 & 1,58 \\
\hline$v$ & 156 & 34 & 15 & 100 & 16 & 3 \\
\hline $\mathbf{P b}$ & 12 & 47 & 93 & 23 & 47 & 52 \\
\hline $\mathbf{R b}$ & 180 & 180 & 270 & 250 & 150 & - \\
\hline $\mathrm{Ba}$ & 1340 & 1330 & 570 & 530 & 800 & 560 \\
\hline Sr & 520 & 500 & 150 & 130 & 320 & 100 \\
\hline $\mathrm{Nb}$ & 11 & 18 & 16 & 15 & 9 & 11 \\
\hline $\mathrm{Zr}$ & 250 & 490 & 200 & 150 & 190 & 53 \\
\hline$Y$ & 74 & 110 & 81 & 49 & 27 & 7 \\
\hline La & 105,9 & 117,8 & 17,34 & 30,29 & 16,44 & \\
\hline $\mathrm{Ce}$ & 218,0 & 244,5 & 45,05 & 73,77 & 35,56 & \\
\hline Nd & 83,97 & 90,75 & 19,67 & 30,97 & 12,72 & \\
\hline Sm & 18,13 & 17,08 & 4,584 & 7,794 & 2,285 & \\
\hline $\mathrm{Eu}$ & 1,783 & 1,934 & 0,464 & 0,621 & 0,396 & \\
\hline Gd & 11,01 & 11,67 & 3,671 & 4,87 & 1,527 & \\
\hline Dy & 10,94 & 10,95 & 4,474 & 5,393 & 1,412 & \\
\hline Ho & 2,15 & 2,10 & 0,927 & 1,089 & 0,299 & \\
\hline $\mathrm{Er}$ & 5,642 & 5,207 & 2,661 & 2,994 & 0,892 & \\
\hline $\mathrm{Yb}$ & 4,280 & 3,589 & 2,753 & 2,80 & 0,860 & \\
\hline Lu & 0,461 & 0,401 & 0,374 & 0,353 & 0,132 & \\
\hline$(\mathrm{La} / \mathrm{Sm}) \mathrm{n}$ & 3,68 & 4,34 & 2,38 & 2,45 & 4,53 & \\
\hline$(\mathrm{Gd} / \mathrm{Yb}) \mathrm{n}$ & 2,10 & 2,63 & 1,08 & 1,41 & 1,43 & \\
\hline$(\mathrm{Eu}) \mathrm{n} / \mathrm{Eu} \mathrm{u}^{*}$ & 0,36 & 0,41 & 0,34 & 0,29 & 0,61 & \\
\hline
\end{tabular}

* extraído de HERZ (1970)

fonte poderia ser a crosta oceânica em subducção (e.g. Condie 1981, Martin 1987, Leake 1990, Tarney \& Saunders 1990).

Uma análise Sm-Nd para o Gnaisse Belo Horizonte forneceu TDM de $3000 \mathrm{Ma}$, sugerindo ser esta a idade do protólito do gnaisse. A migmatização a 2860+14/-10 Ma associa-se a um evento de deformação intensa do Gnaisse Belo Horizonte, com desenvolvimento da foliação principal, orientada preferencialmente segundo $\mathrm{N}-\mathrm{S}$, e dobramento apertado de baixo ângulo.

O Complexo Belo Horizonte foi afetado por um evento de granito gênese no Neoarqueano, representado pela intrusão do Granito Santa Luzia, em 2.712+5/-4 Ma. Evidências indiretas 


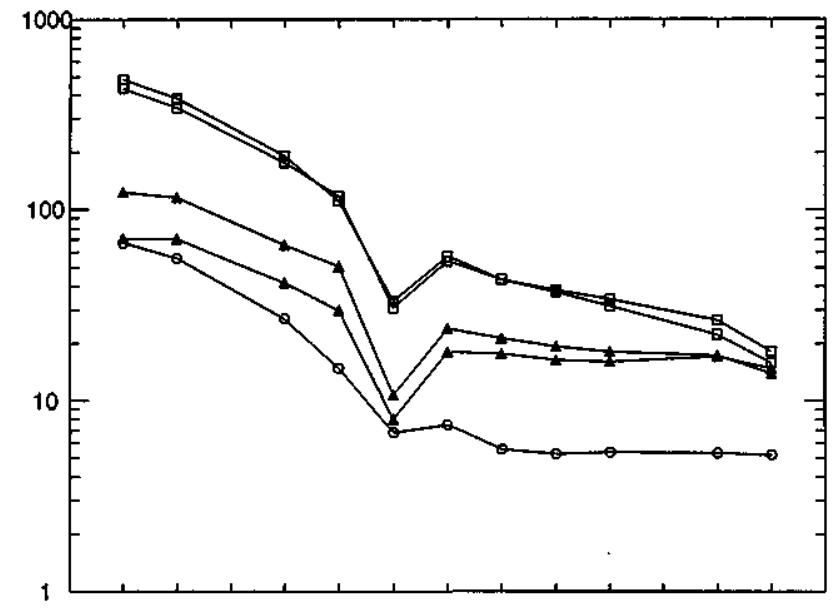

La Ce Pr Nd Sm Eu Gd Dy Ho Er Tm Yb Lu

Figura 9 - Curvas de elementos terras raras, normalizadas aos condutos (valores de normalização de Evensen et ai. 1978), para o Granito Santa Luzia (quadrados vazios), Granito General Carneiro (triângulos preenchidos) e Granodiorito Ibirité (círculos vazios).

Figure 9 - Chondrite-normalized REE patterns (norm values from Evensen et al. 1978) for the Santa Luzia granite (open squares), General Carneiro granite (filled triangles) and Ibirité granodiorite (open circles).

indicam que o Granito General Carneiro posicionou-se nessa mesma época. Igualmente contemporânea foi a intrusão do Granodiorito Ibirité, datado por U-Pb (zircão) em $2.698 \pm 18$ $\mathrm{Ma}$ (Chemale Jr. et al. 1993).

A intrusão dos granitos Santa Luzia e General Carneiro parece relacionar-se aos estágios finais da cratonização ar- queana nesta porção setentrional do Quadrilátero Ferrífero. Em outros crátons arqueanos, os estágios finais da evolução da crosta continental são representados por granitos potássicos, pouco volumosos e de caráter isolado, bastante semelhantes aos corpos estudados no Complexo Belo Horizonte. Pode-se citar, como exemplo, as suítes graníticas Mpageni e Sicunusa, no Cráton Kaapval da África do Sul. Plutonitos dessa natureza são geralmente associados a processos de retrabalhamento da crosta tonalítica primitiva (e.g. Robb 1983). Admite-se que os granitos Santa Luzia e General Carneiro poderiam ter-se originado da fusão, em níveis crustais mais profundos, do próprio Gnaisse Belo Horizonte. $\mathrm{O}$ padrão, relativamente semelhante, das curvas de elementos terras raras dos plutonitos e da curva média do gnaisse é compatível com estaproposta.de derivação. Entretanto, certas características, como as altas razões $\mathrm{Rb} / \mathrm{Sr}$ do Granito General Carneiro, indicam a contribuição de outras fontes para sua geração, possivelmente rochas supracrustais.

O Complexo Belo Horizonte foi afetado de forma significativa pelo Evento Transamazônico, registrado pelo sistema isotópico $\mathrm{U}-\mathrm{Pb}$ nas titanitas do Gnaisse Belo Horizonte e mobilizado migmatítico. As análises de titanita definiram a idade de $2.041 \pm 5$ Ma para o pico metamórfíco do Evento Transamazônico.

Agradecimentos Este trabalho contou com financiamento da FAPEMIG (processo $n^{\circ}$ CEX-24/91) e FAPESP (processo ${ }^{\circ}$ 91/0434-0). Agradece-se ao Químico Robson Cota Oliveira e às técnicas Kênia Júnia de Oliveira e Nívia R. V. de Melo, do Centro de Pesquisa Professor Manuel Teixeira da Costa (IGC-UFMG), a realização de parte da análises. Os autores agradecem as valiosas críticas e sugestões da Prof. Dra. Tânia Mara Dussin e de dois revisores anônimos.
BARKER, F. 1979. Trondhjemite: definition, environment and hypothesis of origin. In: BARKER, F. ed. Trondhjemites, Dacites and Related Rocks. Amsterdan, Elsevier. p. 1-12.

CARNEIRO, M.A. 1992. O Complexo Metamórfico Bonfim Setentrional (Quadrilátero Ferrifero, Minas Gerais): Litoestratigrafia e evolução geológica de um segmento de crosta continental do Arqueano. São Paulo, 233 p. (Tese de Doutoramento, Universidade de São Paulo).

CHEMALE JR, F; BABINSKI, M. VAN SCHMUS, W.R. 1993. U/Pb dating of granitic-gneissic rocks from the Belo Horizonte and Bonfim complexes, Quadrilátero Ferrífero (Brazil). Report for CNPq and NSFEAR Project on São Francisco Cráton Margin Transect Project, 16p. (inédito).

CONDE, K.C. 1981. Archean Greenstone Belts. Amsterdan, Elsevier. 434p.

EVENSEN, N.M.; HAMILTON, P.J.; CTNIONS, R.K. 1978. Rare-earth abundances in chondritic meteorites. Geochimica et Cosmochimica Acta, 42:1199-1212.

FIGUEIREDO, M.C.H. \& BARBOSA, J.S.F. 1993. Terrenos metamórficos de alto grau do Cráton do São Francisco. In: DOMINGUEZ, J.M.L \& MISI, A. eds. O Cráton do São Francisco. Salvador, SBG-SGMCNPq, p.63-84.

G AIR, J.E. 1962. Geology and ore deposits of the Nova Lima and Rio Acima quadrangles. U.S. Geological Survey Professional Paper, 341-A:1-87.

GROSSI SAD, J.H. \& DUTRA, C.V. 1989. Fracionamento dos elementos terras raras e suas aplicações em metalogênese: comportamento geoquímico em sistemas diversos. In: FORMOSO, M.L.L.; NARDI, L.V.S.; HARTMANN, L.A. eds. Geoquímica dos elementos terras raras no Brasil. CPRM/DNPM, SBGq, p. 123-142.

HERZ, N. 1970. Gneissic and igneous rocks of the Quadrilátero Ferrífero, Minas Gerais, Brazil. U.S. Geological Survey Professional Paper, 641-B: $1-58$.

LEAKE, B.E. 1990. Granite magmas: their sources, initiation and consequences of emplacement. Journal of the Geological Society London, 147:579-589.

MACHADO, N. \& CARNEIRO, M. A. 1992. U-Pb evidence of late Archean tectono-thermal activity in the southem São Francisco shield, Brazil. Canadian Journal of Earth Sciences, 29:2341-2346.

MACHADO, N.; NOCE, C.M.; LADEIRA, E.A.; BELO DE OLIVEIRA, O. A. 1992. U-Pb Geochronology of Archean magmatism and Proterozoic metamorphism in the Quadrilátero Ferrífero, southern São Fran- cisco craton, Brazil. Geological Society of America Bullettin, 104:1221-1227.

MANIAR P.D. \& PICCOLI, P.M. 1989. Tectonic discrimination of granitoids. Geological Society of America Bulletin, 101:635-643.

MARTIN, H. 1987. Archean and modern granitoids as indicators of changes in geodynamic processes. Revista Brasileira de Geociências, 17(3/4):360-365.

NOCE, C.M. 1995. Geocronologia dos eventos magmáticos, sedimentarese metamórficos na região do Quadrilátero Ferrifero, Minas Gerais. São Paulo, 128 p. (Tese de Doutoramento, Universidade de São Paulo).

O'CONNOR, J.T. 1965. A classification of quartz-rich igneous rocks based on feldspar ratios. U.S. Geological Survey Professional Paper, 5258:79-84.

POMERENE, J.B. 1964. Geology of Belo Horizonte, Ibirité and Macacos quadrangles. U.S. Geological Survey Professional Paper, 341-D:1-84.

ROBB, L.J. 1983. Geological and chemical characteristics of late granite plutons in the Barberton region and Swaziland with an emphasis on the Dalmein pluton: A review. Special Publication Geological Society of South Africa, 9:153-167.

SCHORSCHER, H.D. 1992. Arcabouco petrográfico e evolucão crustalde terrenos pré-cambrianos do nordeste de Minas Gerais: Quadrilátero Ferrifero, Espinhaço Meridional e domínios granito-gnáissicos adjacentes. São Paulo, 394p. (Tese de Livre Docência, Universidade de São Paulo).

SUN, S.s. \& McDONOUGH, W.F. 1989. Chemical and isotopic systematics of oceanic basalts: implications for mantle composition and processes. In: SAUNDERS, A.D. \& NORRY, M.J. eds. Magmatism in the ocean basins. Geol. Soc. Lond. Spec. Publ., p.313-345.

TARMEY, J. \& SAUNDERS, A. 1990. Crustal growth mechanisms and mantle evolution. In: INTERNATIONAL ARCHAEAN SYMPOSIUM, 3, Perth, 1990. Extended Abstracts...Perth, Geoconferences (W.A.) Inc., p.451-452.

THORNTON, C.P. \& TUTTLE, O.F. 1969. Chemistry of igneous rocks I. Differentiation Índex. American Journal of Science, 258:664-684.

Manuscrito A875 Recebido em 15 de novembro de 1996 Revisão dos autores em 15 de abril de 1997 Revisão aceita em 15 de junho de 1997 